\title{
Value of examining buffy coats for intragranulocytic micro-organisms in patients with fever
}

\author{
JEAN-PAUL STUDER, MICHEL P GLAUSER, MARC SCHAPIRA
}

British Medical fournal, 1979, 1, 85-86

\section{Summary and conclusions}

To determine the significance of the presence of intragranulocytic micro-organisms in the blood buffy coat in patients with suspected infection, buffy coat examination and blood cultures were simultaneously performed in 455 consecutive patients with fever. There was no general correlation between the finding of intragranulocytic micro-organisms in the buffy coat and positive blood cultures. Patients with persistent bacteraemia and sterile blood cultures were, however, shown to have persistently positive buffy coat findings on repeated examination. These patients, who had culture-negative endocarditis or catheter-associated infections, had sterile blood cultures because of antibiotic treatment.

Repeated positive findings in the buffy coat may therefore be valuable in detecting patients with persistent bacteraemia, but sporadic findings of micro-organisms in the buffy coats of acutely ill patients seem to have little diagnostic value.

\section{Introduction}

The value of examining blood smears for rapidly diagnosing bacterial $^{1-9}$ and fungal ${ }^{10}$ systemic infections has been studied in conditions such as fulminant bacteraemia, ${ }^{1-5}$ hyposplenism, ${ }^{6}$ and bacterial endocarditis. ${ }^{*}$ Smears have usually been examined from patients with positive blood cultures, ${ }^{5}$ ' but in one study of disseminated gonococcal infection intragranulocytic Neisseria gonorrheae were specifically identified by immunofluorescence in the absence of viable micro-organisms in the blood. ${ }^{9}$

We performed blood cultures and examined buffy coat layers in unselected hospital patients with fever to determine the diagnostic value of finding micro-organisms in the buffy coat.

\section{Patients and methods}

Four hundred and fifty-five consecutive patients with rectal temperatures of over $37^{\circ} \mathrm{C}$ who were suspected of having bacterial infection underwent simultaneous buffy coat examination and blood culture. Three hundred and twenty-six of the patients were admitted with fever; 129 were already in hospital when they developed fever. Altogether 225 of the patients underwent repeat examinations during their stay in hospital. Twenty conscious patients admitted to hospital for self-poisoning were used as controls.

Buffy-coat preparation-Each patient's ear lobe was cut with a sterile blade and the blood drawn into a microhaematocrit tube (Clay-Adams, length $75 \mathrm{~mm}$; internal diameter $0.56 \mathrm{~mm}$ ). After five minutes' centrifugation at $2000 \mathrm{~g}$ the tube was cut $1 \mathrm{~mm}$ above the buffy layer. The buffy coat was then spread on to a glass cover and

\footnotetext{
Division of Infectious Diseases, Department of Internal Medicine, Centre Hospitalier Universitaire Vaudois, Lausanne, Switzerland JEAN-PAUL STUDER, MD, chief resident MICHEL P GLAUSER, MD, consultant physician MARC SCHAPIRA, MD, chief resident
}

dried for 10 minutes at room temperature, and Gram and methylene blue stains were performed. Each smear was examined for at least 30 minutes by two independent investigators who had no knowledge of the clinical condition. The buffy coat was considered positive if it contained at least two micro-organisms within two or more polymorphonuclear cells.

Blood cultures-Blood obtained from an arm vein was cultured aerobically and anaerobically in trypticase soy broth (Hemobact A and $\mathrm{B}$, Orion Diagnostica, Helsinki). Unless positive, cultures were incubated at $37^{\circ} \mathrm{C}$ for a week before being considered to be sterile. At least three aerobic and three anaerobic cultures were performed in each patient.

\section{Results}

Intragranulocytic micro-organisms were found in buffy coat specimens from 126 of the 455 patients with fever $\left(28^{\circ}{ }_{0}\right)$, while none of the afebrile controls had positive buffy coat specimens $\left(\chi^{2}\right.$ with Yates's correction $=6.19 ; \mathrm{P}=0.025)$. Sixty of the 455 patients $(13 \%)$ had positive blood cultures, but in only 18 were both buffy coat and blood culture findings positive. The incidence of micro-organisms in the buffy coat was similar among patients with sterile blood cultures $\left(108 / 395 ; 27^{\circ}\right)$ and among those with positive blood cultures $(18 / 60$; $30^{\circ}$ ). No correlation could therefore be found between the presence of intragranulocytic micro-organisms in the buffy coat and a positive blood culture in patients with fever and suspected infection.

The 108 patients who had micro-organisms in the buffy coat but sterile blood cultures fell into two groups according to the time the buffy coat examination was performed during their stay in hospital.

Group 1-Seventy-four patients (table I) with negative blood cultures had micro-organisms in the buffy coat on admission. Intra-

TABLE I-Clinical diagnosis in 74 febrile patients who presented with intragranulocytic micro-organisms and sterile blood cultures on admission

\begin{tabular}{|c|c|c|c|c|}
\hline \multirow{2}{*}{ Clinical diagnosis } & \multirow{2}{*}{$\begin{array}{c}\text { No of } \\
\text { patients }\end{array}$} & \multicolumn{2}{|c|}{ Nature of infection } & \multirow{2}{*}{$\begin{array}{l}\text { No who had } \\
\text { had antibiotic } \\
\text { treatment }\end{array}$} \\
\hline & & Bacterial & Viral & \\
\hline $\begin{array}{l}\text { Pneumonia } \\
\text { Urinary tract infection } \\
\text { Cutaneous infection } \\
\text { Endocarditis } \\
\text { CNS infection } \\
\text { Biliary infection }\end{array}$ & $\begin{array}{r}46 \\
8 \\
7 \\
6 \\
4 \\
3\end{array}$ & $\begin{array}{r}36 \\
8 \\
7 \\
6 \\
2 \\
3\end{array}$ & $\begin{array}{r}10 \\
0 \\
0 \\
0 \\
2 \\
0\end{array}$ & $\begin{array}{r}10 \\
3 \\
1 \\
3 \\
0 \\
0\end{array}$ \\
\hline Total & 74 & $62(84 \%)$ & $12(16 \%)$ & $17(23 \%)$ \\
\hline
\end{tabular}

granulocytic micro-organisms were found in $12(16 \%)$ patients with clinical and serological evidence of viral infection. Moreover, intragranulocytic Gram-positive cocci were found in eight patients with documented Gram-negative urinary infection, which cast further doubt on the significance of finding intragranulocytic micro-organisms in acutely ill patients. Buffy coat examination was carried out repeatedly in 25 of the 74 patients after admission. The intragranulocytic micro-organisms disappeared within a few days in 19 of these patients. In six patients, however, they remained present for one to four weeks. In all of these patients bacterial endocarditis was strongly suspected on clinical grounds. Positive blood cultures were delayed for one to three weeks in three of these patients, all of whom had received prior antibiotic treatment. In two others culturenegative endocarditis was confirmed at necropsy. The sixth was clinically cured by four weeks of antibiotic treatment.

Group 2-The second group of patients with positive buffy coat and sterile blood cultures consisted of 34 febrile patients who had severe underlying disease and had been in hospital for five or more days (table II). Thirty-three had an indwelling catheter (intravenous 
intra-arterial, intravesical, or endotracheal), and 24 were undergoing antibiotic treatment. The intragranulocytic micro-organisms that were observed (see figure) were Gram-positive cocci in 15 patients, yeasts in five patients, and both Gram-positive cocci and yeasts in 14 patients. For reasons that are unclear, patients with intragranulocytic yeasts, alone or associated with Gram-positive cocci, had a less severe outcome than patients showing Gram-positive cocci alone: two patients out of 19 with intragranulocytic yeasts died, compared with nine out of 15 with Gram-positive cocci alone $(P=0.003$ by Fisher's exact test). Removal of the catheter(s) and modification of antibiotic treatment in patients with intragranulocytic Gram-positive cocci who survived resulted in the disappearance of fever and of the intragranulocytic micro-organisms. No treatment other than catheter removal was necessary in patients with intragranulocytic yeasts alone

TABLE II-Clinical picture in 34 febrile patients suspected of having infection and presenting intragranulocytic micro-organisms together with sterile blood cultures while in hospital

\begin{tabular}{|c|c|c|c|}
\hline Clinical picture & $\begin{array}{c}\text { No of } \\
\text { patients }\end{array}$ & $\begin{array}{l}\text { No who had } \\
\text { had antibiotic } \\
\text { treatment }\end{array}$ & $\begin{array}{c}\text { No with } \\
\text { indwelling } \\
\text { catheters }\end{array}$ \\
\hline \multirow{2}{*}{$\begin{array}{l}\text { Neurological disorders (cerebrovascular } \\
\text { disease, encephalitis, tetanus) } \\
\text { Cardiac catheterisation or cardiac surgery } \\
\text { End-stage neoplasms } \\
\text { Pancreatitis, liver cirrhosis } \\
\text { Bone surgery } \\
\text { Acute respiratory failure } \\
\text { End-stage renal failure }\end{array}$} & 7 & 5 & 7 \\
\hline & $\begin{array}{l}7 \\
5 \\
4 \\
4 \\
4 \\
3\end{array}$ & $\begin{array}{l}4 \\
2 \\
4 \\
3 \\
4 \\
2\end{array}$ & $\begin{array}{l}7 \\
4 \\
4 \\
4 \\
4 \\
3\end{array}$ \\
\hline Total & 34 & $24(71 \%)$ & $33\left(97^{\circ}\right)$ \\
\hline
\end{tabular}

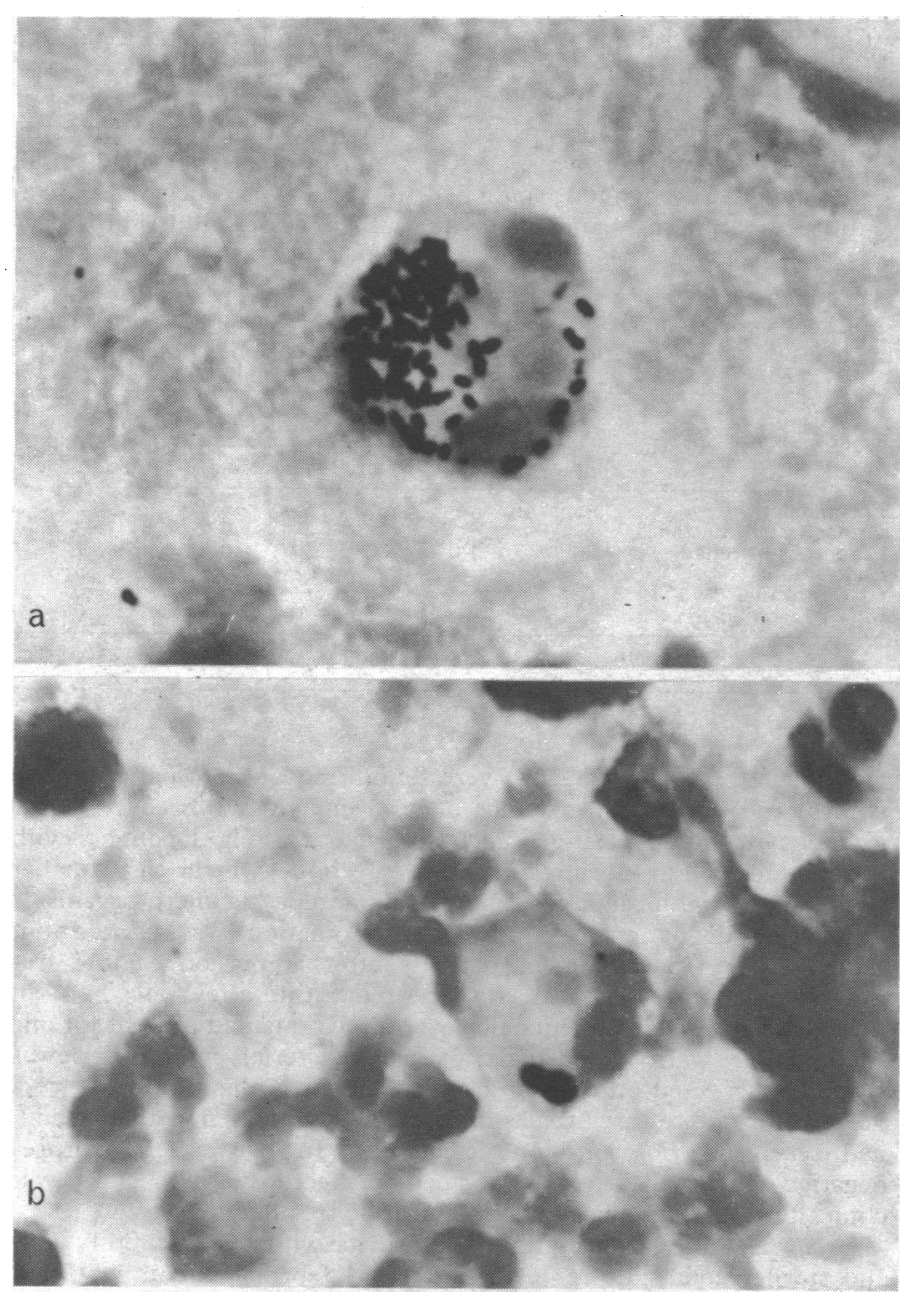

(a) Intragranulocytic Gram-positive cocci and (b) budding yeasts, as seen in positive buffy coat specimens $(\times 500)$.

\section{Discussion}

Our findings confirm and extend those of another study, ${ }^{11}$ which showed that no correlation could be found between the presence of intragranulocytic bacteria in the blood buffy coat layer and a positive blood culture. As in other series, ${ }^{45}$ only a third of the patients whose blood cultures showed bacteria had. micro-organisms in the buffy coat.

Nevertheless, our study has defined a group of patients in whom buffy coat examination is most helpful: hospital in-등 patients with fever and sterile blood cultures, most of themos having antibiotic treatment, who had indwelling catheters. In $\mathbb{\odot}$ such patients low-grade bacteraemia or fungaemia that had persisted for a long time may have been reflected by the presence ${ }^{\infty}$ of intragranulocytic micro-organisms on repeated testing, while $\vec{\odot}$ blood cultures remained sterile mainly because of antibiotic $\overrightarrow{ }$ treatment. Moreover, in a second group of patients the suspected ${ }_{\sigma}$ diagnosis of culture-negative endocarditis after repeatedly윽 positive findings in the buffy coat was confirmed in five out of 3 . six patients. This also underlined the observation that positive $\vec{\sigma}$ intragranulocytic micro-organisms are mainly found in patients $\frac{G}{\sigma}$ with persistent bacteraemia, as occurs in bacterial endocarditis. ${ }^{12} \mathrm{O}$

Our study therefore suggests that repeated findings of $\infty$ intragranulocytic micro-organisms in the buffy coat of patients음 with fever but sterile blood cultures may indicate that they have $\vec{\omega}$ persistent bacteraemia. In contrast, positive buffy coat findings $\vec{\omega}$ on isolated occasions in acutely ill patients do not seem to have any diagnostic significance.

\section{References}

1 Andrewes, F W, Lancet, 1906, 1, 1172.

${ }^{2}$ Humphrey, A A, American fournal of Clinical Pathology, 1944, 14, 358.

${ }^{3}$ Falkinburg, L W, et al, fournal of the American Medical Association, $1962,182,868$

4 McCabe, W R, and LaPorte, J J, Annals of Internal Medicine, 1962, 57, 141. ํํำ

5 Smith, H, Australasian Annals of Medicine, 1966, 15, 210.

- Torres, J, and Bisno, A L, American fournal of Medicine, 1973, 55, 851.

7 Brooks, G F, Pribble, A H, and Beaty, H N, Archives of Internal Medicine, $\frac{O}{3}$ 1973, 132, 673.

8 Powers, D L, and Mandell, G L, Fournal of the American Medical Association, 1974, 227, 312.

Tronca, E, et al, fournal of Infectious Diseases, 1974, 129, 583.

${ }_{10}$ Portnoy, J, et al, New England fournal of Medicine, 1971, 285, 1010.

11 Carlson, B E, and Andersen, B R, Fournal of the American Medical Association, 1976, 235, 1465.

12 Werner, A S, et al, fournal of the American Medical Association, 1967, 202, 127.

(Accepted 19 October 1978)

ONE HUNDRED YEARS AGO The following interesting caseN is reported by Dr Wittelshöfer, in the Wiener Medizinische Presse, $\omega$ January 25th, 1879. An infantry soldier received, on August 16th, 1878 , a gun-shot wound of the left thigh, just below the great trochanter. He was carried to the ambulance, but an examination of the $\bar{\Phi}$ wound failed to reveal the presence of a bullet. On his arrival at the ${ }^{\text {? }}$ hospital in Marburg (August 22nd), blood was passed per urethram; this was the only occasion in which there was hæmaturia, but the urine웅

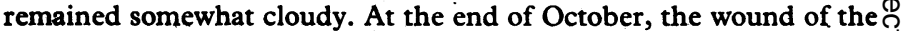
thigh having healed, the patient was dismissed; difficulty of mictu-ब rition then ensued, and, at the beginning of December, a piece of the thick linen (three centimètres long and one centimètre wide) of which drawers were made and worn at the time of the injury, was expelled from the urethra. When he was admitted to Dr Billroth's clinic, it was found that a foreign body was present in the bladder. Median lithotomy was performed, and the bullet, coated with phosphates, was? extracted. The wound caused by the operation healed, and the patient left the hospital. The urine, however, did not regain its normal character; and, on January 17 th, after a certain amount of straining, a small portion of his blue uniform (one centimetre long and half a centimetre wide) was discharged from the urethra. After this, the patient completely regained his health. (British Medical fournal, 1879.) 